\title{
Towards health benefits in chronic respiratory diseases: pulmonary rehabilitation
}

\author{
Martijn A. Spruit ${ }^{1}$ and Enrico M. Clini $^{2}$
}

Affiliations: 'Program Development Center, ClRO+, Center of expertise for chronic organ failure, Horn, The Netherlands. ${ }^{2} \mathrm{DU}$ of Medical and Surgical Sciences, University of Modena and Ospedale Villa Pineta, Modena, Italy.

Correspondence: M.A. Spruit, Program Development Center, CIRO+, Center of Expertise for Chronic Organ Failure, Hornerheide 1, 6085 NM, Horn, The Netherlands. E-mail: martijnspruit@aciro-horn.nl

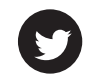

@ERSpublications

A series on pulmonary rehabilitation: how best to implement it http://ow.ly/mMEzi

In 1895, Dr Charles Denison, a Professor of Diseases of the Chest and of Climatology at the University of Denver, was the first to state that daily walks, hygiene and dietary are important to acquire mental relaxation, happiness and prosperity in "pulmonary invalids" [1]. Notwithstanding, it took another 74 years before PЕTTY et al. [2] described a "comprehensive care programme" for individuals with "chronic airway obstruction" in a landmark peer-reviewed article [2]. This is still regarded as the first article on the short-term and long-term efficacy of rehabilitation for patients suffering from a chronic pulmonary disease. The first international statement on pulmonary rehabilitation with a strong recommendation for its use in the management of patients with chronic obstructive pulmonary disease (COPD) was first published in 1992, and has been offered to physicians, and other healthcare professionals, by the scientific community [3]. That recommendation is still supported by the latest American Thoracic Society (ATS)/European Respiratory Society (ERS) Statement of Pulmonary Rehabilitation [4], as well as by the Global Initiative for COPD (GOLD) strategy document for the diagnosis and management COPD [5].

To date, pulmonary rehabilitation is defined by the ATS and ERS as a comprehensive intervention based on a thorough patient assessment, followed by patient-tailored therapies, which include, but are not limited to, exercise training, education and behaviour change, designed to improve the physical and psychological condition of people with chronic respiratory disease and to promote the long-term adherence to healthenhancing behaviours [4]. Daily symptoms, lower-limb muscle function, exercise capacity and health status, will improve following pulmonary rehabilitation in individuals with chronic respiratory diseases [6-12]. Moreover, healthcare costs are likely to decrease following a pulmonary rehabilitation course [13, 14]. So, it seems fair to conclude that pulmonary rehabilitation is a cardinal part of COPD management, and a useful intervention in other chronic respiratory diseases [15].

Taking all these facts into account, the Editorial Board of the European Respiratory Review (ERR) decided to invite a group of international experts to write a series on pulmonary rehabilitation. In the first article, which appeared in the June edition of the ERR, GLOECKL et al. [16] provided practical recommendations for exercise training in patients with COPD, which is still considered as the cornerstone of pulmonary rehabilitation programmes [16]. Indeed, optimisation of the physical condition of individuals with a chronic respiratory disease is an important goal in their rehabilitation course [17-23]. Optimisation of the psychological condition, as well as the promotion of the long-term adherence to health-enhancing

Received: June 012013 | Accepted: June 052013

Conflict of interest: None declared.

Provenance: Submitted article, peer reviewed.

Copyright @ERS 2013 
behaviours have also been identified by the ATS/ERS Task Force on Pulmonary Rehabilitation as additional goals of pulmonary rehabilitation [4]. These goals may be achieved partially following the exercise-training component of pulmonary rehabilitation. The non-exercising parts of rehabilitation, however, seem to add an additional value in achieving these newly identified goals. Therefore, it is important to understand the content and the efficacy of these non-exercising components. It this issue of the ERR, HiLl et al. [24] summarise the content and efficacy of smoking cessation, optimising pharmacotherapy, assisting with early identification and treatment of exacerbations, managing acute dyspnoea, increasing physical activity, improving body composition, promoting mental health, facilitating advance care planning, and establishing social support networks in individuals with COPD. In particular, these approaches should be equally considered and incorporated within rehabilitation programmes to optimise effective self-management of chronic respiratory diseases [4]. However, this implies that at the initial intake and assessment should contain much more than just lung function tests, a dyspnoea score and a field exercise tests. Other outcomes, e.g. body composition, comorbidities, physical activity, problematic activities of daily life, mental health, life-sustaining treatment preferences, and the home-environment, also need to be evaluated [25-28]. Based on the results of this comprehensive assessment, a patient-tailored programme can then be compiled by the interdisciplinary rehabilitation team. Indeed, multiple dedicated healthcare professionals are necessary to deal with the multifaceted clinical presentation of individuals with chronic respiratory disease who have been referred for pulmonary rehabilitation [4]. To achieve interdisciplinarity, healthcare professionals need to combine their clinical activities into joint activities for the same patient-oriented treatment goal(s), and create new approaches by thinking across conventional professional boundaries [29].

To complete this thematic series, two other articles will deal on how to adapt the pulmonary rehabilitation programme to patients with chronic respiratory disease other than COPD, and consider the complex comorbidities and their impact in individuals with COPD who are generally referred for rehabilitation. This series should be of interest to members of the ERS, as the topics are very timely, the articles within the series are easy to read and aim at providing practical recommendations. Indeed, it is expected that the reviews will create additional awareness in the health community covering the importance of pulmonary rehabilitation, enabling clinicians to appropriately set up new programmes as well as broadening the scope of existing ones. This seems necessary as, to date, accessibility to pulmonary rehabilitation programmes is often still very poor $[30,31]$.

\section{References}

Denison C. Exercise and Food for Pulmonary Invalids. Denver, The Chain \& Hardy Co, 1895.

Petty TL, Nett LM, Finigan MM, et al. A comprehensive care program for chronic airway obstruction. Methods and preliminary evaluation of symptomatic and functional improvement. Ann Intern Med 1969; 70: 1109-1120.

3 Donner CF, Howard P. Pulmonary rehabilitation in chronic obstructive pulmonary disease (COPD) with recommendations for its use. Report of the European Respiratory Society Rehabilitation and Chronic Care Scientific Group (S.E.P.C.R. Rehabilitation Working Group). Eur Respir J 1992; 5: 266-275.

4 Spruit MA, Singh SJ, Garvey C, et al. An Official American Thoracic Society/European Respiratory Society statement: key concepts and advances in pulmonary rehabilitation - an executive summary. Am J Respir Crit Care Med (in press).

5 Vestbo J, Hurd SS, Agusti AG, et al. Global strategy for the diagnosis, management, and prevention of chronic obstructive pulmonary disease: GOLD executive summary. Am J Respir Crit Care Med 2013; 187: 347-365.

6 Ries AL, Bauldoff GS, Carlin BW, et al. Pulmonary rehabilitation: joint ACCP/AACVPR evidence-based clinical practice guidelines. Chest 2007; 131: Suppl. 5, 4S-42S

7 Vincent E, Sewell L, Wagg K, et al. Measuring a change in self-efficacy following pulmonary rehabilitation: an evaluation of the PRAISE tool. Chest 2011; 140: 1534-1539.

8 Spruit MA, Gosselink R, Troosters T, et al. Low-grade systemic inflammation and the response to exercise training in patients with advanced COPD. Chest 2005; 128: 3183-3190.

9 Ambrosino N, Venturelli E, Vagheggini G, et al. Rehabilitation, weaning and physical therapy strategies in chronic critically ill patients. Eur Respir J 2012; 39: 487-492.

10 Wijkstra PJ, Wempe JB. New tools in pulmonary rehabilitation. Eur Respir J 2011; 38: 1468-1474.

11 Vogiatzis I. Strategies of muscle training in very severe COPD patients. Eur Respir J 2011; 38: 971-975.

12 Spruit MA, Wouters EF. New modalities of pulmonary rehabilitation in patients with chronic obstructive pulmonary disease. Sports Med 2007; 37: 501-518.

13 Griffiths TL, Phillips CJ, Davies S, et al. Cost effectiveness of an outpatient multidisciplinary pulmonary rehabilitation programme. Thorax 2001; 56: 779-784.

14 Puhan MA, Gimeno-Santos E, Scharplatz M, et al. Pulmonary rehabilitation following exacerbations of chronic obstructive pulmonary disease. Cochrane Database Syst Rev. 2011; 10: CD005305.

15 Wagg K. Unravelling self-management for COPD: what next? Chron Respir Dis 2012; 9: 5-7.

16 Gloeckl R, Marinov B, Pitta F. Practical recommendations for exercise training in patients with COPD. Eur Respir Rev. 2013; 22: 178-186.

17 Blanco I, Santos S, Gea J, et al. Sildenafil to improve respiratory rehabilitation outcomes in COPD: a controlled trial. Eur Respir J 2013 [In press DOI: 10.1183/09031936.00176312]

18 Leung RW, McKeough ZJ, Peters MJ, et al. Short-form Sun-style t'ai chi as an exercise training modality in people with COPD. Eur Respir J 2013; 41: 1051-1057. 
19 Gouzi F, Préfaut C, Abdellaoui A, et al. Blunted muscle angiogenic training-response in COPD patients versus sedentary controls. Eur Respir J 2013; 41: 806-814.

20 Huppmann P, Sczepanski B, Boensch M, et al. Effects of in-patient pulmonary rehabilitation in patients with interstitial lung disease. Eur Respir J 2013; 42: 444-453.

21 McNamara RJ, McKeough ZJ, McKenzie DK, et al. Water-based exercise in COPD with physical comorbidities: a randomised controlled trial. Eur Respir J 2012; 41: 1284-1291.

22 Rubin LJ. Exercise training for pulmonary hypertension: another prescription to write? Eur Respir J 2012; 40: 7-8.

23 Grunig E, Lichtblau M, Ehlken N, et al. Safety and efficacy of exercise training in various forms of pulmonary hypertension. Eur Respir J 2012; 40: 84-92.

24 Hill K, Vogiatzis I, Burtin C. The importance of components of pulmonary rehabilitation, other than exercise training, in COPD. Eur Respir Rev 2013; 22: 405-413.

25 Spruit MA, Vanderhoven-Augustin I, Janssen PP, et al. Integration of pulmonary rehabilitation in COPD. Lancet 2008; 371: 12-13.

26 Vanfleteren LE, Spruit MA, Groenen M, et al. Clusters of comorbidities based on validated objective measurements and systemic inflammation in patients with chronic obstructive pulmonary disease. Am J Respir Crit Care Med 2013; 187: 728-735.

27 Crisafulli E, Gorgone P, Vagaggini B, et al. Efficacy of standard rehabilitation in COPD outpatients with comorbidities. Eur Respir J 2010; 36: 1042-1048.

28 Annegarn J, Meijer K, Passos VL, et al. Problematic activities of daily life are weakly associated with clinical characteristics in COPD. J Am Med Dir Assoc 2012; 13: 284-290.

29 Wikipedia. Interdisciplinarity. http://en.wikipedia.org/wiki/Interdisciplinarity Date last accessed: May 31, 2013. Date last updated: June 16, 2013

30 Wadell K, Janaudis Ferreira T, Arne M, et al. Hospital-based pulmonary rehabilitation in patients with COPD in Sweden-A national survey. Respir Med 2013 [In press DOI: 10.1016/j.rmed.2013.04.019]

31 Brooks D, Sottana R, Bell B, et al. Characterization of pulmonary rehabilitation programs in Canada in 2005. Can Respir J 2007; 14: 87-92. 